\title{
To analyse the semen for various parameters with special reference to lifestyle factors
}

\author{
Abhinav Aswal*, Sangeeta Sharma, Rani Bansal, Anjali Khare
}

Department of Pathology, Subharti Medical College, Swami Vivekanand Subharti University, Meerut, Uttar Pradesh, India

Received: 14 April 2017

Accepted: 08 May 2017

*Correspondence:

Dr. Abhinav Aswal.

E-mail: kilroyabni@gmail.com

Copyright: () the author(s), publisher and licensee Medip Academy. This is an open-access article distributed under the terms of the Creative Commons Attribution Non-Commercial License, which permits unrestricted non-commercial use, distribution, and reproduction in any medium, provided the original work is properly cited.

\section{ABSTRACT}

Background: Male factor is responsible for infertility in $23 \%$ cases. Semen analysis is the cornerstone of infertility evaluation as it provides information on the functional status of seminiferous tubules, epididymis and accessory sex glands. Reports in recent years has shown that incidence of male infertility has increased as a result of various factors such as lifestyle, environmental pollution and stress.

Methods: This prospective study was conducted on patients reporting for semen analysis in Department of Pathology, Subharti Medical College. The duration of the study was from October 2014 to September 2016 with a study sample of 196 cases. Semen analysis was done by manual method according to WHO 2010 criteria.

Results: According to fertility scoring, out of 196 cases, 51 (26\%) were infertile cases. With respect to infertile cases $82.4 \%$ were alcoholic, $80.4 \%$ tobacco smokers, $25.5 \%$ were tobacco chewers. These results were statistically significant. Out of 45 cases of oligozoospermia $37(82.2 \%)$ were alcoholic, $36(80 \%)$ were tobacco smoker and 10 $(22.2 \%)$ were tobacco chewers. Out of 54 cases of asthenozoosperma $38(70.4 \%)$ were alcoholic, $37(68.5 \%)$ were tobacco smoker and $11(20.4 \%)$ were tobacco chewers.

Conclusions: Alcohol consumption, tobacco smoking and tobacco chewing have a significant negative effect on the process of spermatogenesis, ultimately affecting sperm concentration, viability and motility. Hence clinician and fertility counselors need to be more focused to control infertility by modifying the life style factors.

Keywords: Infertility, Lifestyle, Semen Analysis

\section{INTRODUCTION}

Semen analysis is the cornerstone of infertility evaluation as it provides information on the functional status of seminiferous tubules, epididymis and accessory sex glands. ${ }^{1}$ Reports in recent years has shown that incidence of male infertility has increased as a result of various factors such as lifestyle, environmental pollution and stress. Alcohol abuse in men has been reported to cause impaired testosterone production, and atrophy of testes, which can result in impotence, infertility and reduced male secondary sexual characteristics. ${ }^{2-4}$ Tobacco consumption is one of the lifestyle factors that is often detrimental to human health as a whole. ${ }^{5}$ Use of cell phones also adversely affects the quality of semen. Leydig cells, seminiferous tubules and spermatozoa are the main targets of the damage by mobile phones on reproductive tract. ${ }^{6-8}$ This study aims to evaluate the impact of these life style cell factors on specific aspects of fertility and semen quality.

\section{METHODS}

This prospective study was conducted on 196 patients who reported for semen analysis in Department of Pathology, Subharti Medical College. The duration of the 
study was from October 2014 to September 2016. Strict exclusion criteria were used since we aimed to study the impact of alcohol consumption, tobacco smoking, tobacco chewing and use of cell phone.

Following strict abstinence of two to six days, samples were collected in a wide mouthed sterile container by masturbation, in the laboratory. All samples were kept at normal room temperature and processed immediately after complete liquefaction and examined as per WHO 2010 guidelines. All semen samples were analysed for 10 primary semen parameters- volume, liquefaction time, sperm concentration, viability, progressive motility, viscosity, particulate matter, agglutination, normal spermeation and headless sperm. Individual parameters were assessed according to WHO 2010.9

The results obtained in the study are presented in tabulated manner in Microsoft Word Excel. Data analysis was done by Statistical Package for the Social Sciences (SPSS) version 19. The Statistical analysis was done by using chi-square test. P-value $<0.05$ was considered as statistically significant and $\mathrm{P}$-value $<0.01$ was taken as highly significant while $\mathrm{P}$-value $>0.05$ was regarded as non-significant.

\section{RESULTS}

In our study, out of 196 cases there were $131(66.8 \%)$ fertile and $51(28.6 \%)$ infertile cases. The sub fertile were $9(4.6 \%)$. The age ranged from 19 year to 50 year. Maximum $127(64.8 \%)$ cases were in age group of 19-30 years. In the infertile cases, $42(82.4 \%)$ cases were alcoholic, $41(80.4 \%)$ cases were tobacco smokers and 13 $(25.5 \%)$ were tobacco chewers. These findings were statistically significant (Table 1-3).

Majority of cases of oligozoospermia and asthenozoospermia were associated with alcohol consumption and tobacco smoking. Out of 45 cases of oligozoospermia $82.2 \%$ cases were alcoholics and $80 \%$ tobacco smoker. Out of 54 cases of asthenozoospermia $70.4 \%$ cases were alcoholics and $68.5 \%$ tobacco smoker. Similarly, out of 39 cases of oligoasthenozoospermia $84.6 \%$ were alcoholics and $82.1 \%$ were tobacco smoker (Table 4).

Table 1: Association of alcohol consumption with fertility score.

\begin{tabular}{|llll|}
\hline \multirow{2}{*}{ Fertility score } & \multicolumn{1}{l}{ Alcohol consumption } & \\
& Present & Absent & Total \\
\hline Fertile & $22(16.8 \%)$ & $109(83.2 \%)$ & $131(100.0)$ \\
\hline Sub fertile & $3(33.3 \%)$ & $6(66.7 \%)$ & $9(100.0)$ \\
\hline Infertile & $42(82.4 \%)$ & $9(17.6 \%)$ & $51(100.0)$ \\
\hline Indeterminate* & $1(20.0 \%)$ & $4(80.0 \%)$ & $5(100.0)$ \\
\hline Total & $68(34.7 \%)$ & $128(65.3 \%)$ & $196(100.0)$ \\
\hline
\end{tabular} $\begin{aligned} & \chi^{2} \text {-Value=69.29; P value<0.001(SIG.); }{ }^{*} \text { Cases in which semen } \\
& \text { did not liquefy. }\end{aligned}$

Table 2: Association of tobacco smoking cases with fertility score.

\begin{tabular}{|lllllll|} 
& \multicolumn{3}{l}{ Tobacco smoking } \\
Fertility score & \multicolumn{2}{l}{ Present } & \multicolumn{2}{l|}{ Absent } & \multicolumn{2}{l|}{ Total } \\
\cline { 2 - 7 } & Fre & \% & Fre & \% & Fre & $\%$ \\
\hline Fertile & 22 & 16.8 & 109 & 83.2 & 131 & 100.0 \\
\hline Sub fertile & 2 & 22.2 & 7 & 77.8 & 9 & 100.0 \\
\hline Infertile & 41 & 80.4 & 10 & 19.6 & 51 & 100.0 \\
\hline Indeterminate* & 1 & 20.0 & 4 & 80.0 & 5 & 100.0 \\
\hline Total & 66 & 33.7 & 130 & 66.3 & 196 & 100.0 \\
\hline
\end{tabular}

$\chi^{2}$ - Value $=66.72 ; \mathrm{P}$ value $<0.001$ (SIG.) $*$ Cases in which semen did not liquefy.

Table 3: Association of tobacco chewing case with fertility score.

\begin{tabular}{|c|c|c|c|c|c|c|}
\hline \multirow{3}{*}{ Fertility score } & \multicolumn{6}{|c|}{ Tobacco chewing } \\
\hline & \multicolumn{2}{|c|}{ Present } & \multicolumn{2}{|c|}{ Absent } & \multicolumn{2}{|l|}{ Total } \\
\hline & Freq & $\%$ & Freq & $\%$ & Freq & $\%$ \\
\hline Fertile & 5 & 3.8 & 126 & 96.2 & 131 & 100.0 \\
\hline Sub fertile & 1 & 11.1 & 8 & 88.9 & 9 & 100.0 \\
\hline Infertile & 13 & 25.5 & 38 & 74.5 & 51 & 100.0 \\
\hline Indeterminate* & 1 & 20.0 & 4 & 80.0 & 5 & 100.0 \\
\hline Total & 20 & 10.2 & 176 & 89.8 & 196 & 100.0 \\
\hline
\end{tabular}

Table 4: Various semen variables.

\begin{tabular}{|lll|}
\hline Semen variable & Number & Percentage \\
\hline Oligozoospermia & 45 & 23.5 \\
\hline Arthenozoospermia & 54 & 27.5 \\
\hline Oligoasthenozoospermia & 39 & 20 \\
\hline Azoospermia & 06 & 3.1 \\
\hline Normozoospermia & 131 & 73.4 \\
\hline
\end{tabular}

\section{DISCUSSION}

Of the myriad of factors that have been blamed for influencing the semen quality, life style factors like alcohol consumption, tobacco smoking and tobacco chewing have attracted much attention in recent time all over the world. In our study, out of 196 cases that were studied $66.8 \%$ as per fertility score were fertile. The sub fertile group had $4.6 \%$ cases and infertile group had $28.6 \%$ cases. Our study had $3.1 \%$ cases of Azoospermia, $23.5 \%$ cases of oligozoospermia and $73.2 \%$ cases of normozoospermia. Our study had $27.5 \%$ cases of asthenozoospermia. These findings corroborated well with other studies on sperm concentration and sperm motility (Table 6).

There is significant relationship between alcohol consumption and infertility. The negative association between alcohol intake and semen quality may be attributed to a direct adverse effect of alcohol on spermatogenesis or it may be a result of differences in lifestyle, health behavior and diet found among high alcohol consumers despite adjustment for these factors. 
Study by Kumar et al on 240 male partner of couple consulting for infertility problem found deterioration in sperm count, total progressive motility and normal sperm morphology among alcohol consumption. ${ }^{10}$ Due study showed association of alcohol with $82.2 \%$ oligozoospermic and $70.4 \%$ asthenozoospermia. Similar study by Gaur et al on 100 alcoholic showed oligozoospermia was much higher amongst alcohol cases $(n=51)$, than controls, indicating progressive damage to testes in direct relation to increasing daily alcohol intake. ${ }^{11}$ These studies showed lesser association of asthenozoospermia as compared to oligozoospermia.

Table 5: Association of lifestyle factors with various semen variables.

\begin{tabular}{|lcccccc|}
\hline & \multicolumn{2}{c}{ Alcohol consumption \% } & \multicolumn{2}{c|}{ Tobacco smoking \% } & \multicolumn{2}{c|}{ Tobacco chewing \% } \\
\hline Semen variable & Present & Absent & Present & Absent & Present & Absent \\
\hline Oligozoospermia (45) & 82.2 & 17.8 & 80 & 20 & 22.2 & 77.8 \\
\hline Asthenozoospermia (54) & 70.4 & 29.6 & 68.5 & 31.5 & 20.4 & 79.6 \\
\hline Oligoasthenozoospermia (39) & 84.6 & 15.4 & 82.1 & 17.9 & 25.6 & 74.4 \\
\hline Azoospermia (06) & 83.3 & 16.7 & 83.3 & 16.7 & 50 & 50 \\
\hline Normozoospermia (131) & 16 & 84 & 16.8 & 83.2 & 3.05 & 96.9 \\
\hline
\end{tabular}

Table 6: Variation in sperm concentration and motility.

\begin{tabular}{|c|c|c|c|c|c|}
\hline Studies comparison & Azoospermia & Oligozoospermia & Normozoospermia & Asthenozoospermia & Normal \\
\hline Our study & $3.1 \%$ & $23.5 \%$ & $73.2 \%$ & $27.5 \%$ & $72.5 \%$ \\
\hline Khushbu et al ${ }^{68}$ & $5.7 \%$ & $25.1 \%$ & $69.2 \%$ & $38.7 \%$ & $61.3 \%$ \\
\hline Jagoo et al ${ }^{70}$ & -- & $25 \%$ & $75 \%$ & $35 \%$ & $65 \%$ \\
\hline Kumar et al ${ }^{71}$ & $7.9 \%$ & $26.3 \%$ & $65.8 \%$ & $36.7 \%$ & $63.3 \%$ \\
\hline
\end{tabular}

Thus, alcohol induced reduction in levels of testosterone, LH and FSH not only hamper their normal morphological development and maturation of spermatozoa, it slows down the sperm production by testicular germ cells, especially in alcoholic.

Present study showed smoking was associated with $16.8 \%$ fertile population as compared to $22.2 \%$ sub fertile and $80.4 \%$ of infertile population. There is a strong association of cigarette smoking with infertility in our study.

In study by Kumar et al, among the oligozoospermia subjects, there was a non-significant lowering of sperm count and total progressive mobility between smoker and non-smokers. ${ }^{10}$ Study by Ramlau Hansen et al showed deleterious effect of tobacco smoking on semen parameter. $^{12}$ Present study showed association of cigarette smoking with $80 \%$ oligozoospermia and $68.5 \%$ Arthenozoospermia case.

Similar studies by gaur et al showed higher number of oligozoospermia in smokers as compared to nonsmoker. ${ }^{11}$ In these study asthenzoospermia was the most dominant semen variable contributing to the semen quality of smokers.

With respect to Tobacco chewing - $10.21 \%$ cases were tobacco chewers. Our study showed tobacco chewing was associated with $3.8 \%$ fertile population as compared to $11 \%$ sub fertile and $25.5 \%$ infertile population. Present study showed association of tobacco chewing with $22.2 \%$ oligozoospermias and $20.4 \%$ asthenozoospermia. The relationship between tobacco chewing and male infertility remain unclear and data specifically addressing this issue are scanty. Kumar et al in their study found oligoasthentetratozoospermia was significantly high among in chewers as compared to non-chewer. ${ }^{10}$

Said et al have reported an increasing trend of oligoasthenotetrazoospermia from mild to moderate to severe with respect to addiction of tobacco chewing. ${ }^{13}$ Life style factors play an important role in the aetiology of various diseases and have also been implicated to cause reproductive impairment. In present study sperm concentration, progressive motility and viability was much lower in subjects exposed to life style factors like alcohol consumption, tobacco smoking and tobacco chewing.

In present study, statistical significance was determined between life style factors like alcohol consumption, tobacco smoking and tobacco chewing and infertile cases. Our results corroborated well with other studies like ones by Gaur et al, Khushbu et al and Kumar et al (Table 6). ${ }^{10,11,14}$ Hence it is evident that alcohol consumption, tobacco smoking and tobacco chewing have a significant negative effect on the process of spermatogenesis, ultimately affecting sperm concentration, viability and motility. Hence clinician and fertility counselors need to be more focused to control infertility by modifying the life style factors. 
Funding: No funding sources

Conflict of interest: None declared

Ethical approval: The study was approved by the Institutional Ethics Committee

\section{REFERENCES}

1. Cooper et al. World Health Organization reference values for human semen characteristics. Human Reprod Update. 2010;16(3):231-45.

2. Guzick DS, Overstreet JW, Factor-Litvak P, Brazil CK, Nakajima ST, Coutifaris C, et al. Sperm morphology, motility, and concentration in fertile and infertile men. N Engl J Med. 2001;345(19):1388-93.

3. Van der Colf AP, Kruger TF, Menkveld R, Seier JV, Finch Am JE, Swart Y, et al. Effect of ethanol on semen characteristics of vervet monkeys. Archives of andrology. 1991;26(1):25-9.

4. Gordon GG, Altman K, Southren AL, Rubin E, Lieber CS. The effect of alcohol administration on sex hormone metabolism in normal men. $\mathrm{N}$ Engl $\mathrm{J}$ Med. 1976;295(15):793-7.

5. Koskinen LO, Collin O, Bergh A. Cigarette smoke and hypoxia induce acute changes in the testicular and cerebral, microcirculation. Ups $\mathrm{J}$ Med Sci. 2000;105:215-26.

6. Agarwal A, Deepinder F, Sharma RK, Ranga G, Li J. Effect of cell phone usage on semen analysis in men attending infertility clinic an observational study. Fertil Steril. 2008;89(1):124-8.

7. LaVignera S, Condorelli RA, Vicari E, D'Agata R, Calogero AE. Effects of the exposure to mobile phones on male reproduction a review of the literature. J Androl. 2012;33(3):350-6.
8. Kesari KK, Kumar S and Behari J. Mobile phone usage and male infertility in wistar rats. Indian J Exp Biol. 2010;47:987-92.

9. World Health Organization. WHO laboratory manual for the examination of human semen and spermcervical mucus interaction. 5th ed. Geneva. 2010.

10. Kumar S, Murarka S, Mishra VV, Gautam AK. Environmental and lifestyle factors in deterioration of male reproductive health Indian J Med Res. 2014;140:S29-35.

11. Gaur DS, Talekar MS, Pathak VP. Alcohol intake and cigarette smoking: impact of two major lifestyle factors on male fertility. Indian J Pathol Microbiol. 2010;53(1):35-40.

12. Ramlau-Hansen $\mathrm{CH}$, Thulstrup AM, Aggerholm AS, Jensen MS, Toft G, Bonde JP. Is smoking a risk factor for decreased semen quality? A cross-sectional analysis. Hum Reprod. 2007;22(1):188-96.

13. Said TM, Kattal N, Sharma RK, Sikka SC, Thomas AJ, Mascha E, et al. Enhanced chemiluminescence assay vs colorimetric assay for measurement of the total antioxidant capacity of human seminal plasma. J Androl. 2003;24(5):676-80.

14. Vaghela K, Oza H, Mishra V, Gautam A, Kumar S. Effect of lifestyle factors on semen quality. Int J Life Sci Scienti Res. 2016;2(5):627-31.

Cite this article as: Aswal A, Sharma S, Bansal R, Khare A. To analyse the semen for various parameters with special reference to lifestyle factors. Int J Reprod Contracept Obstet Gynecol 2017;6:2589-92. 